\title{
Violência contra a pessoa idosa na região Nordeste do Brasil no período de 2012 a 2018
}

\author{
Violence against the elderly in the Northeast \\ region of Brazil from 2012 to 2018
}

\section{Isabel Vitor de Souza Lima' ${ }^{1}$ Cátia Suely Palmeira ${ }^{2}$ Tássia Teles Santana de Macedo ${ }^{3}$ (1)}

${ }^{1}$ Autora para correspondência. Escola Bahiana de Medicina e Saúde Pública (Salvador). Bahia, Brasil. isabellima1307@gmail.com ${ }^{2-3}$ Escola Bahiana de Medicina e Saúde Pública (Salvador). Bahia, Brasil. catia_palmeira@yahoo.com.br, tassiateles85@gmail.com

RESUMO | OBJETIVO: Descrever a violência contra a pessoa idosa na região Nordeste do Brasil no período de 2012 a 2018. METODOLOGIA: Estudo descritivo ecológico de série temporal utilizando dados secundários do Sistema de Informação de Agravos de Notificação - SINAN no período de 2012 a 2018, disponíveis no site DATASUS. A população foi constituída por idosos na faixa etária de 60 anos e mais. Elegeram-se as variáveis: região de ocorrência, ano de notificação, sexo, raça/cor, escolaridade, local de ocorrência, tipo de violência e característica do agressor. RESULTADOS: No período foram registrados 18.357 casos de violência contra o idoso, ocorrendo aumento, com maior proporção no estado de Pernambuco (6668; 36,3\%), com predominância no sexo feminino (9393; 51,2\%), pardos (11.250; 61,3\%) e $\leq 3$ anos de estudo (4.238; 60,5\%). Observa-se que a violência acontece predominantemente na própria residência dos idosos (11.174; $60,9 \%)$, sendo a violência física a mais frequente $(28,0 \%)$, seguida por negligência/abandono (17,3\%). Maior número de registro de casos de violência foi cometido pelos filhos (5578; 43\%). CONCLUSÃO: O registro de casos de violência contra os idosos aumenta a cada ano na região Nordeste, sendo as mulheres com baixa escolaridade as mais acometidas. Os dados apresentados apontam à necessidade de intervenções especificas de prevenção e controle da violência contra o idoso.

DESCRITORES: Abuso de idosos. Violência. Idosos. Sistema de Informação em Saúde. Epidemiologia.
ABSTRACT | OBJECTIVE: To describe violence against the elderly in the Northeast region of Brazil from 2012 to 2018. METHODOLOGY: Descriptive ecological time series study using secondary data from the Notifiable Disease Information System - SINAN for the period 2012 to 2018, available on the DATASUS website. The population consisted of elderly people aged 60 years and over. Variables were chosen: region of occurrence, year of notification, gender, race/color, education, place of occurrence, type of violence and characteristics of the aggressor. RESULTS: In the period, 18,357 cases of violence against the elderly were registered, with an increase, with the highest proportion in the state of Pernambuco $(6668 ; 36.3 \%)$, with a predominance of females $(9393 ; 51.2 \%)$, brown $(11,250)$; $61.3 \%)$ and $\leq 3$ years of education $(4,238 ; 60.5 \%)$. It is observed that violence occurs predominantly in the elderly's own homes $(11,174 ; 60.9 \%)$, with physical violence being the most frequent (28.0\%), followed by neglect/abandonment (17.3\%). Children committed the greatest number of cases of violence (5578; 43\%). CONCLUSION: The number of cases of violence against the elderly increases every year in the Northeast region, with women with low education being the most affected. The data presented point to the need for specific interventions to prevent and control violence against the elderly.

DESCRIPTORS: Elder abuse. Violence. Seniors. Health Information System. Epidemiology. 


\section{Introdução}

O envelhecimento populacional é um fenômeno evidente em todo o mundo. Tal processo envolve não só mudanças nos aspectos demográficos, mas também epidemiológicos representados pelo surgimento e aumento de agravos específicos da população idosa. ${ }^{1}$ Uma das consequências da longevidade é o aumento da violência contra o idoso, constituindo-se em um grande desafio para a saúde pública principalmente para os países em desenvolvimento e demandando uma resposta abrangente das politicas públicas. ${ }^{2-3}$

Mundialmente, estima-se que 1 em cada 6 idosos já sofreu algum tipo de violência e que $15,7 \%$ das pessoas com 60 anos ou mais estão sujeitas a abusos e mal tratos. ${ }^{4}$ Apesar de a gravidade de suas consequências, grandes lacunas permanecem na estimativa da prevalência de abuso de idosos. 5

É preciso ressaltar que nem todos os episódios de violência que ocorrem com os idosos chegam ao conhecimento das autoridades sanitárias, considerando-se assim uma subestimação desta estimativa, porque idosos muitas vezes têm medo de relatar casos de abuso à família, amigos ou às autoridades e porque os dados sobre a extensão do problema em instituições de cuidados são escassos. ${ }^{6-7}$ De acordo com a Organização Mundial de Saúde, prevê-se que o número de pessoas afetadas aumente ainda mais, visto que muitos países estão enfrentando um rápido envelhecimento da população sem o devido preparo para esta mudança demográfica. ${ }^{4}$

É oportuno destacar que as mudanças advindas da idade podem levar às alterações no processo fisiológico e no estilo de vida, incluindo a redução da capacidade física e mental do ser humano levando-os a tornarem-se mais vulnerável à violência na medida em que o grau de dependência aumenta. $2,8 \mathrm{Em}$ sociedades onde não há um preparo para o fenômeno da longevidade, a exposição das pessoas ao adoecimento e a violência é ainda maior.

A violência contra a pessoa idosa pode ser definida como qualquer ato ou falta de ato que resulte em algum dano ou sofrimento desnecessário, proposital ou impensado, podendo ocorrer principalmente dentro de uma relação em que haja confiança. ${ }^{9}$ Esta pode ser praticada dentro ou fora do ambiente familiar, por algum membro da família ou por outras pessoas que exerçam um papel de superioridade sobre a pessoa idosa, a exemplo dos cuidadores. ${ }^{-9}$ Ainda de acordo com a OMS, fenômeno da violência cometida com a pessoa idosa pode trazer consequências físicas e psicossociais, como hematomas, pequenos arranhões, isolamento, ansiedade, depressão hospitalizações e incapacidades, podendo constituir-se em danos relativamente pequenos até danos graves e permanentes, ou mesmo a morte..$\underline{9}$

As distintas formas pelas quais a violência contra a pessoa idosa costuma aparecer podem se distinguir em cinco categorias. A violência física, que é o uso intencional de força ou poder com o intuito de causar dor e sofrimento; o abuso sexual, cujo pode envolver qualquer atividade sexual não consentida; a violência psicológi$\mathrm{ca}$, que inclui qualquer conduta que causa dano emocional; abuso financeiro, que envolve uma apropriação ilícita de bens e ganhos pessoais e monetários de uma pessoa idosa; por fim, a negligência e o abandono, uma das mais frequentes formas de violência, geralmente por parte de um cuidador, interferindo nas necessidades de saúde física e mental de um idoso.9-10

No Brasil, os casos de suspeita ou confirmação de violência contra os idosos são objetos de notificação compulsória desde a implantação do Estatuo do Idoso em 200311, sendo esta notificação também uma obrigação pelos atendimentos realizados em serviço de saúde com a Lei no. 12.461, de 26 de julho de 2011.12 Assim, o combate à violência contra os idosos, com amparo na legislação, ganhou ferramentas mais efetivas de identificação do problema.

Ainda no que concerne a proteção e cuidado com o idoso, o Estatuto do Idoso por meio da Lei no 10.741, de $1^{\circ}$ de outubro de 2003, assume um papel fundamental na maneira como a velhice é vista e tratada na sociedade brasileira, determinando que todos (família, comunidade, sociedade e poder público), com absoluta prioridade, têm a obrigação de garantir à pessoa idosa, entre vários outros direitos, o direito à saúde, à alimentação, ao respeito, enfim a uma vida digna na sua convivência familiar e comunitária. ${ }^{13}$ 
Neste contexto, os profissionais de saúde, incluindo os de enfermagem, possuem um importante papel no enfrentamento deste problema, por meio da escuta sensível e observação atenta da comunicação, do comportamento, das expressões e dos fatores de risco.,.14 Mesmo sendo um desafio, o enfrentamento da violência contra os idosos, muitos casos poderiam ser evitados, se houvesse maior empenho e ações de intervenção e educação direcionadas aos familiares e cuidadores de idosos. 14

Diante da gravidade epidemiológica e social da violência cometida contra os idosos, é relevante conhecer como esse agravo tem ocorrido em algumas regiões do país, de forma a contribuir para ampliar as informações sobre este problema e assim subsidiar estratégias de prevenção. Na região Nordeste, existe escassez de pesquisa sobre este problema.

Assim configurou-se como pergunta investigativa "Qual o perfil da violência contra o idoso na região Nordeste do Brasil no período de 2012 a 2018?". Deste modo, o objetivo deste estudo é descrever a violência contra a pessoa idosa na região Nordeste do Brasil no período de 2012 a 2018.

\section{Método}

Trata-se de um estudo descritivo, ecológico de série temporal realizado com dados secundários obtidos por meio de consultas ao SINAN (Sistema de Informações de Agravos de Notificação), disponibilizados pelo Departamento de Informática do Sistema Único de Saúde (DATASUS), no endereço eletrônico www.datasus.gov.br, informações de saúde (TABNET)/epidemiológicas e morbidade. O SINAN é nutrido pela notificação e verificação de casos de doenças e agravos de notificação compulsória a partir dos serviços de saúde, que encaminham uma via da notificação para a Vigilância Epidemiológica das Secretarias Municipais de Saúde, seguindo para a Secretaria Estadual de Saúde (SESA) e para o Ministério da Saúde.
A população do estudo foi constituída pelos casos de violência contra a pessoa idosa na região Nordeste do Brasil, registrados Sistema de Informações de Agravos de Notificação - SINAN no período de 2012 a 2018. Os dados foram acessados em setembro/outubro de 2020. Foram incluídos idosos na faixa etária de 60 anos e mais. Excluiu-se da análise os casos registrados como ignorados para quaisquer variáveis selecionadas.

As variáveis selecionadas para análise foram as já existentes no sistema: região de ocorrência, ano de notificação, sexo, raça/cor, escolaridade, local de ocorrência, tipo de violência e característica do agressor.

Para a análise dos dados foram elaboradas tabelas utilizando o programa Excel e Word do software Microsoft Office 2016 e do Programa Tabnet do DATASUS. As informações relacionadas às variáveis de interesse foram analisadas por meio da frequência absoluta e frequência relativa e apresentados em tabelas e gráficos.

O estudo seguiu as normas da Resolução 466/12 do Conselho Nacional de Ética em Pesquisa, e utilizou dados secundários de domínio público, dessa forma, não apresenta implicações éticas e morais e dispensa a autorização do comitê de ética em pesquisa.

\section{Resultados}

No período analisado de 2012 a 2019 foram registrados 18.357 casos de violência contra a pessoa idosa, evidenciando Pernambuco como o estado com o maior número de casos (6.668 casos), representando $36,3 \%$ do total. No que se refere ao ano de notificação pode-se observar que 2018 foi o ano em que se registrou mais violência contra a pessoa idosa na (Tabela 1). Observa-se um aumento de $158 \%$ de registro de casos entre 2012 a 2018. 
Tabela 1. Violência doméstica, sexual e outras violências contra a pessoa idosa por ano de notificação e Estado de ocorrência na região Nordeste no período de 2012 a 2018

\begin{tabular}{cccccccccccc}
\hline $\begin{array}{c}\text { Ano da } \\
\text { Notificação }\end{array}$ & MA & PI & CE & RN & PB & PE & AL & SE & BA & Total \\
\cline { 2 - 11 } & $\mathbf{2 0 1 2}$ & 175 & 106 & 94 & 91 & 356 & 350 & 129 & 45 & 259 & 1605 \\
$\mathbf{2 0 1 3}$ & 188 & 193 & 125 & 132 & 486 & 536 & 127 & 80 & 375 & 2242 \\
$\mathbf{2 0 1 4}$ & 120 & 73 & 201 & 120 & 135 & 533 & 162 & 68 & 415 & 1827 \\
$\mathbf{2 0 1 5}$ & 113 & 101 & 302 & 123 & 150 & 712 & 169 & 83 & 414 & 2167 \\
$\mathbf{2 0 1 6}$ & 73 & 157 & 482 & 138 & 65 & 1173 & 184 & 42 & 479 & 2793 \\
$\mathbf{2 0 1 7}$ & 104 & 141 & 595 & 158 & 170 & 1547 & 241 & 79 & 542 & 3577 \\
$\mathbf{2 0 1 8}$ & 144 & 166 & 744 & 183 & 172 & 1817 & 208 & 105 & 607 & 4146 \\
\hline
\end{tabular}

Fonte: Ministério da Saúde/SVS - Sistema de Informação de Agravos de Notificação - Sinan Net

Na tabela 2, estão as informações da violência contra a pessoa idosa segundo sexo, raça/cor, escolaridade e estados de notificação na região Nordeste. No que diz respeito ao sexo, os dados mostraram que a violência foi maior no sexo feminino $(9393 ; 51,2 \%)$ do que no masculino $(8963 ; 48,8 \%)$ casos. No que se refere à cor/raça, os casos de violência foram acentuadamente maiores em idosos que se declararam pardos (11250; 61,3\%). Quanto à escolaridade, os dados revelam que a violência ocorre mais entre os idosos com menor escolaridade de 1 a 3 anos de estudos (2167; 30,9\%) e para os que não têm instrução ou menos de 1 ano de estudo $(2071 ; 29,6 \%)$. Estes dois últimos somados totalizam $60,5 \%$ do total. Observa-se que para os idosos que têm 15 anos ou mais de estudo é registrado menor frequência de violência (228; 3,3\%).

Tabela 2. Violência doméstica, sexual e outras violências contra a pessoa idosa segundo sexo, raça/cor, escolaridade e região de notificação na região Nordeste no período de 2012 e 2018

\begin{tabular}{|c|c|c|c|c|c|c|c|c|c|c|}
\hline \multirow{2}{*}{ Variáveis } & \multicolumn{10}{|c|}{ Estados } \\
\hline & MA & PI & CE & RN & PB & PE & $\mathrm{AL}$ & SE & BA & Total \\
\hline \multicolumn{11}{|l|}{ Sexo } \\
\hline Masculino & 406 & 509 & 1320 & 543 & 724 & 2667 & 752 & 229 & 1813 & 8963 \\
\hline Feminino & 511 & 428 & 1223 & 402 & 810 & 4000 & 468 & 273 & 1278 & 9393 \\
\hline \multicolumn{11}{|l|}{ Raça/cor } \\
\hline Branca & 110 & 145 & 434 & 226 & 146 & 907 & 117 & 95 & 290 & 2470 \\
\hline Preta & 105 & 85 & 120 & 46 & 31 & 373 & 52 & 50 & 343 & 1205 \\
\hline Parda & 562 & 528 & 1853 & 541 & 1247 & 4546 & 485 & 153 & 1335 & 11250 \\
\hline Amarela & 7 & 17 & 3 & 2 & 3 & 38 & 12 & 2 & 20 & 104 \\
\hline Indígena & 3 & 1 & 8 & - & 8 & 12 & 11 & - & 7 & 50 \\
\hline Ignorado & 130 & 161 & 125 & 130 & 99 & 792 & 543 & 202 & 1096 & 3278 \\
\hline \multicolumn{11}{|l|}{$\begin{array}{c}\text { Escolaridade (anos de } \\
\text { estudo) }\end{array}$} \\
\hline $\begin{array}{l}\text { Sem instrução e }<1 \\
\text { ano }\end{array}$ & 146 & 163 & 547 & 86 & 222 & 430 & 170 & 34 & 273 & 2071 \\
\hline 1 a 3 anos & 165 & 177 & 614 & 103 & 104 & 556 & 104 & 29 & 315 & 2167 \\
\hline 4 a 7 anos & 142 & 103 & 289 & 43 & 193 & 346 & 46 & 20 & 209 & 1391 \\
\hline 8 a 10 anos & 55 & 39 & 89 & 23 & 88 & 144 & 27 & 9 & 119 & 593 \\
\hline $11-14$ anos & 31 & 53 & 82 & 27 & 64 & 160 & 22 & 6 & 108 & 553 \\
\hline$\geq 15$ anos & 14 & 11 & 26 & 12 & 48 & 74 & 13 & 6 & 24 & 228 \\
\hline Não determinado & 363 & 390 & 893 & 648 & 813 & 4938 & 838 & 398 & 2036 & 11317 \\
\hline
\end{tabular}

Fonte: Ministério da Saúde/SVS - Sistema de Informação de Agravos de Notificação - Sinan Net 
De acordo com os dados da tabela 3, observa-se que a violência acontece predominantemente na própria residência dos idosos $(11174 ; 60,9 \%)$, e depois em via pública $(2446 ; 13,3 \%)$.

Tabela 3. Violência doméstica, sexual e outras violências contra a pessoa idosa segundo local de ocorrência e região de notificação na região Nordeste, no período de 2012 a 2018

\begin{tabular}{|c|c|c|c|c|c|c|c|c|c|c|}
\hline \multirow{2}{*}{$\begin{array}{l}\text { Local de } \\
\text { ocorrência }\end{array}$} & \multicolumn{10}{|c|}{ Estado } \\
\hline & MA & PI & CE & $\mathbf{R N}$ & PB & PE & $A L$ & SE & BA & Total \\
\hline Residência & 636 & 557 & 1562 & 479 & 1010 & 4675 & 520 & 302 & 1433 & 11174 \\
\hline Via pública & 147 & 111 & 514 & 97 & 264 & 558 & 169 & 35 & 548 & 2443 \\
\hline Bar ou Similar & 14 & 32 & 33 & 10 & 26 & 52 & 10 & 4 & 61 & 242 \\
\hline Comércio/Serviços & 12 & 25 & 25 & 8 & 5 & 55 & 8 & 8 & 22 & 168 \\
\hline Habitação Coletiva & 3 & 6 & 13 & 7 & 9 & 47 & 9 & 7 & 19 & 120 \\
\hline Escola & 2 & 1 & 7 & - & 2 & 3 & 2 & 1 & 5 & 23 \\
\hline Indústria/construção & 4 & - & 3 & 1 & - & 7 & 1 & - & 2 & 18 \\
\hline $\begin{array}{l}\text { Local de pratica } \\
\text { esportiva }\end{array}$ & - & - & 2 & - & - & 7 & 3 & - & - & 12 \\
\hline Outros & 41 & 21 & 265 & 26 & 32 & 335 & 34 & 15 & 81 & 850 \\
\hline Ignorado/branco & 58 & 184 & 119 & 317 & 186 & 929 & 464 & 130 & 920 & 3307 \\
\hline Total & 917 & 937 & 2543 & 945 & 1534 & 6668 & 1220 & 502 & 3091 & 18357 \\
\hline
\end{tabular}

Com relação à natureza da violência (Figura 1) as mais frequentes foram a violência física $(28,0 \%)$, seguida da violência por negligência e abandono (17,3\%). A violência sexual foi a que apresentou menor percentual $(1,0 \%)$.

Figura 1. Percentual de casos registrados de violência contra a pessoa idosa de segundo o tipo de violência na região Nordeste no período de 2012 a 2018

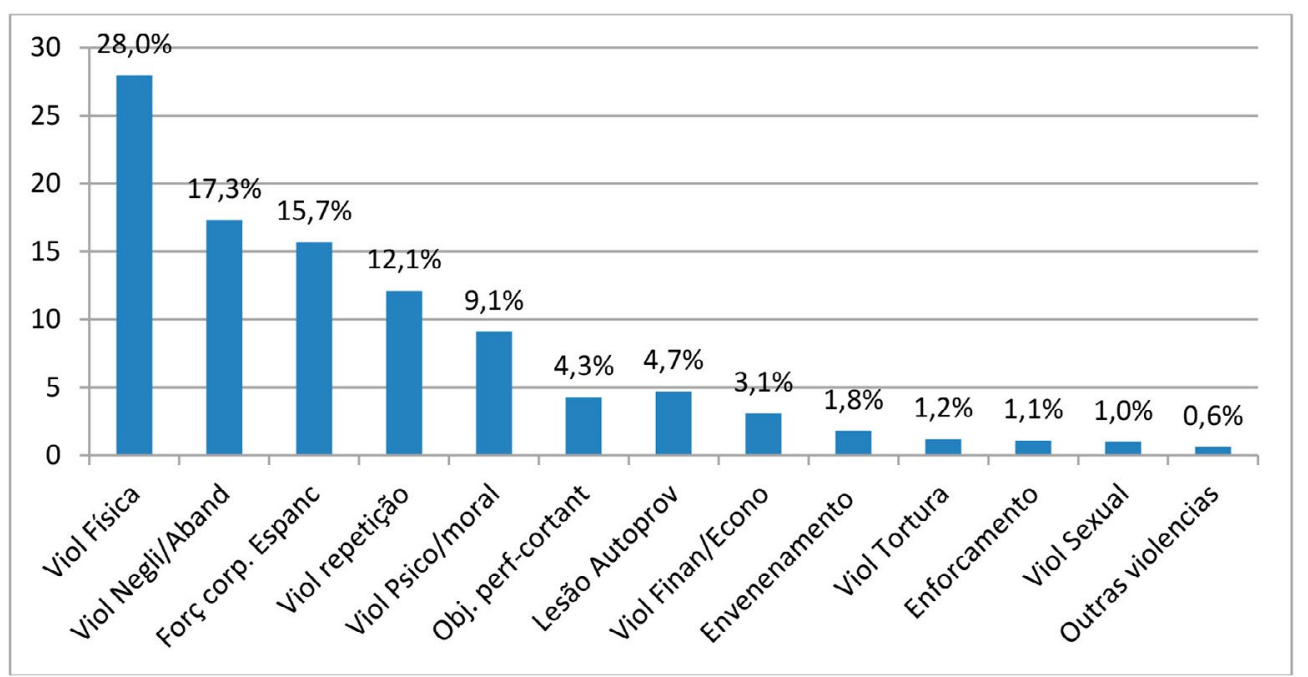

Fonte: Ministério da Saúde/SVS - Sistema de Informação de Agravos de Notificação - Sinan Net

Quanto ao perfil do agressor observa-se que o maior número de registro de casos de violência foi cometido pelos filhos (43,0\%), seguido por desconhecido (15,2\%) (Figura 2). 


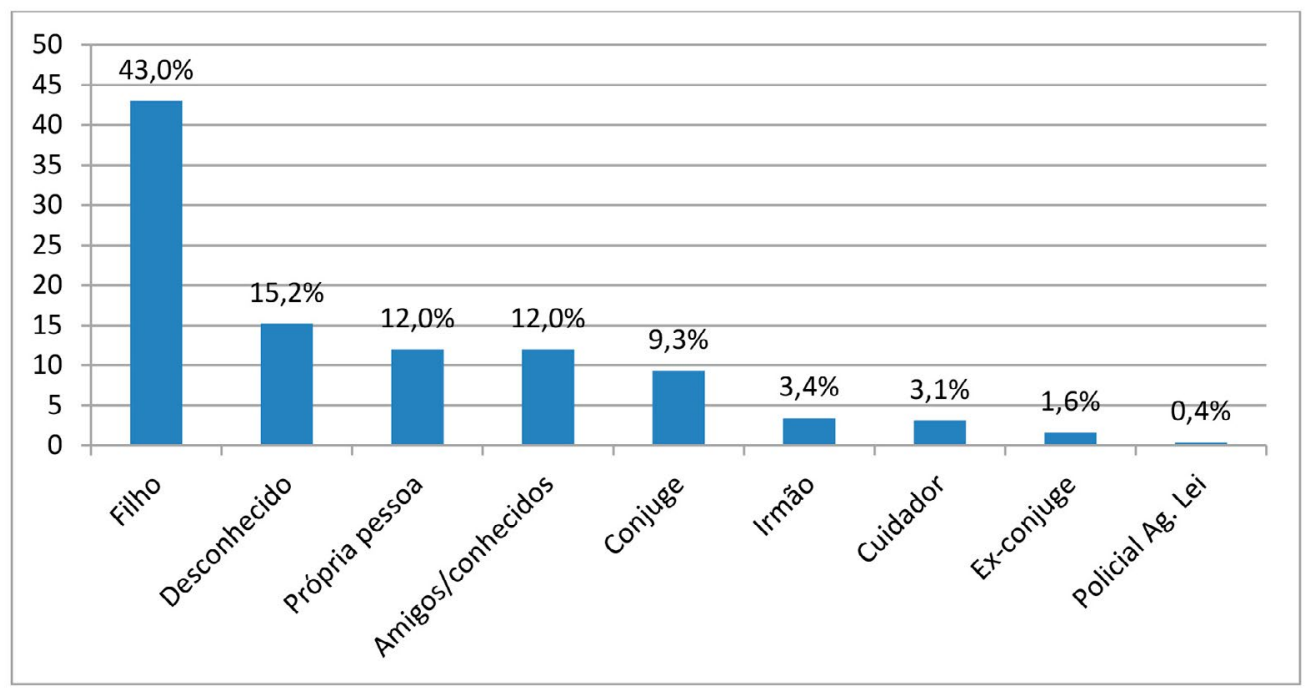

Fonte: Ministério da Saúde/SVS - Sistema de Informação de Agravos de Notificação - Sinan Net

\section{Discussão}

Como se assinalou na introdução, a violência contra os idosos é um grande e complexo problema de saúde pública, constituído por diversos fatores interligados relacionados ao ambiente familiar, a vítima e ao autor da agressão. $\frac{15-16}{16}$

De acordo com os dados apresentados, o estudo demonstra que o número de casos de violência contra a pessoa idosa mostrou-se maior no ano de 2018, sendo a região pernambucana a de maior número em todos os anos. Pesquisa realizada sobre violência contra idosos em Recife na capital de Pernambuco aponta um incremento das notificações pelos serviços de saúde, passando de 1,46\%, em 2009, para 3,37\%, em 2012.17

Ainda que seja notável o crescimento da prevalência da violência contra a pessoa idosa, estudos que tratam do tema ainda são escassos, dificultando comparações entre as diversas regiões do território brasileiro. A literatura considera que há uma insuficiência de informações sobre a natureza e a extensão do abuso de idosos em países de baixa renda, e a maioria dos estudos existentes foi realizado em países de alta renda, fazendo com que estratégias em relação à prevenção e ao tratamento permanecem incipientes. 3.

O perfil identificado no estudo revelou que a maioria dos idosos que são vítimas de violência são as mulheres. Estudos indicam que as mulheres idosas são mais propensas do que os homens idosos a vivenciaram maus tratos, especificamente, abuso emocional e financeiro.,18 Maior probabilidade de as mulheres sofrerem violência pode ser explicada pela maior longevidade e consequentemente maior perda de independência nas atividades

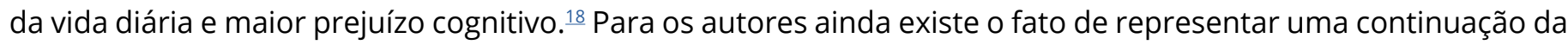
violência praticada pelo parceiro e também que em algumas culturas, as mulheres são mais socialmente treinadas para suportar maus tratos.

Resultados de pesquisa realizada com dados obtidos em Delegacias do Idoso em três municípios, Ribeirão Preto (São Paulo), Teresina (Piauí) e João Pessoa (Paraíba), no período de 2009 a 2013, verificou também que a violência contra idosos é maior no sexo feminino e que os familiares das vítimas são os principais agressores, mesmo quando os familiares não residiam com a vítima..$^{19}$ 
O achado de maior frequência de violência contra o idoso com menos anos de estudo justifica-se pelo fato de a baixa escolaridade estar ligada as condições sociais precárias e de pobreza. Uma pessoa idosa que vive num contexto de pobreza pessoal e familiar tem muito menos possibilidade de escapar dessa situação do que idosos que tem melhores condições financeiras. ${ }^{20-21}$ Estes dados também revelam importantes desigualdades sociais na ocorrência da violência contra os idosos.

Com relação ao local de ocorrência da violência contra os idosos foi possível identificar que a mesmas acontece na grande maioria em suas próprias residências. Explicações para este fato se referem à qualidade das relações da vítima com seus familiares e o grau de dependência, aspectos estes que podem determinar a forma cujo cuidador conduzirá a situação, agindo de forma positiva ou negativa. 16 Para estes autores, o idoso sofre maior risco de abuso quando é mais dependente para a realização de atividades cotidianas, quando os agressores são mais dependentes dos idosos, principalmente os jovens que necessitam de moradia e assistência financeira, reafirmando que existe uma relação de interdependência entre o agressor e a vítima.

Embora a família deva ser local do principal sistema de suporte da pessoa idosa na sociedade, o despreparo dos familiares e cuidadores, o histórico de violência entre os parentes e a carência econômica, são considerados fatores que podem levar a família a cometer maus tratos contra os idosos ${ }^{22}$, e assim transformar a própria residência em um ambiente de risco para ocorrência de violência. Revisão integrativa recente evidencia que quem vive sozinho ou com filhos tem dez vezes mais chances de sofrer violência. Para os autores do estudo, discutir e viver em conflito com familiares ou amigos é considerado fator de riscos para violência..$\underline{17}$

Outras diversas modificações estruturais ocorridas na sociedade quanto às relações familiares (divórcios e novas uniões), valorização do idoso, inserção da mulher no mercado de trabalho, movimentos migratórios, envelhecimento populacional e urbanização acelerada podem também vir a influenciar a maior frequência da violência contra a pessoa idosa no ambiente familiar. ${ }^{23}$ Desse modo, pode-se afirmar que existem diversos fatores para a violência doméstica, não apenas os fatores socioeconômicos.
A pessoa idosa é vítima de diversos tipos de violências ao mesmo tempo, tanto verbal como física. ${ }^{15}$ No presente estudo, no que se refere à natureza da violência, a de maior prevalência foi a de lesão corporal, seguida da negligência/abandono. Estes subtipos de violência também são observados em recente Metaanálise que analisou resultados de estudos de base populacional. ${ }^{17}$ Estes achados podem ser justificados pela fragilidade e dependência da vítima idosa diante do seu agressor, pois geralmente este tipo de violência ocorre nos lares ou em instituições asilares. $\underline{.2}^{2}$

A negligência individual, familiar, social ou institucional em relação às necessidades da pessoa idosa representa uma forma cruel de violência. Muitas vezes, este tipo de violência é velado, mas estão presentes na família que abandona o seu idoso, nas instituições e serviços públicos por meio de inadequação das instalações, do isolamento das pessoas idosas em seus aposentos, da falta ou precariedade de assistência à sua saúde. $\underline{20}$

Com relação ao perfil do agressor, vale destacar que neste estudo o maior número de registro de casos de violência foi cometido pelos filhos, e que somado aos outros familiares como cônjuge e irmãos, fica evidente que são os familiares os maiores perpetradores desses atos de maus tratos. Estes dados estão de acordo com estudo que demostra que os agressores eram principalmente familiares (companheiro em $28 \%$, filho em $20 \%$ e filha em $12 \%$ ) no que diz respeito às vítimas que viviam em casa, sendo que os fatores de risco mais comuns relacionados aos agressores foram sentir-se sobrecarregado e coabitar com a vítima (33\% cada). .4 Em virtude desse contexto, é importante que familiares que são cuidadores devam estar preparados e receber apoio para cessar tais situações. 21

Revisão integrativa realizada com o objetivo de fornecer uma ampla visão sobre a violência contra os idosos e para ajudar a mapear semelhanças, temas e lacunas na literatura sobre o tema, afirma que este é um problema internacional crescente com diferentes manifestações em diferentes países e culturas. ${ }^{3}$ Os autores alegam ainda que a violência física é o tipo de maus-tratos encontrados de forma mais consistente nos estudos analisados. 
Os recursos disponíveis para prevenir e intervir no abuso de idosos, e o grau em que são coordenados, variam consideravelmente em todo o mundo, porém em alguns países, as campanhas de conscientização podem ter precedência sobre os esforços de intervenção e prevenção, dado o conhecimento público limitado do problema. $\underline{3}$

No que tange a atenção à saúde, identificar casos de idoso que vivenciam qualquer tipo de violência é fundamental. Para tal se faz necessário que o profissional de saúde mantenha uma postura de observador e que esteja atento a qualquer indício de maus tratos ou sofrimento decorrente de situação de violência, de forma a resolver este problema, ou até mesmo favorecer a prevenção. ${ }^{25}$ Os autores ressaltam que os enfermeiros inseridos na atenção básica possuem um vínculo com esse público, e, dessa forma, devem utilizar dessa posição favorecida para atuar no atendimento ao idoso com o olhar para tais problemas.

Destaca-se que, embora a violência seja frequentemente descrita como um problema das pessoas mais jovens, ela persiste na vida adulta e tem um grande impacto nos adultos mais velhos. Entretanto a violência contra esta população tem recebido ainda atenção insuficiente dos pesquisadores, profissionais e serviços de saúde, gestores, políticas públicas e justiça criminal até agora. Desta forma ressalta que os índices de violência contra esta população devem estar subnotificados, uma vez que os idosos temem revelar que estão em situação de violência, considerando que na maioria das vezes, os perpetradores são os próprios familiares e, por isso, temem expor a circunstância em que vivem. ${ }^{21}$

Vale ressaltar que no Brasil não possui programas voltados para a reabilitação de agressores, e nem sempre a prisão dos mesmos pode evitar futura agressões. Assim, a depender da relação que o idoso tenha com o agressor, eles podem ignorar sua própria segurança a fim de proteger o agressor pelo medo ou pelo desejo de mudar comportamento do mesmo, levando a não o denunciar e aumentar a invisibilidade já existente deste tipo de violência.

Mais pesquisas sobre esta temática podem ajudar elucidar o contexto da violência e seus fatores associados na perspectiva de implementar intervenções dirigidas, não só as vítimas, como também aos agressores. O desenvolvimento de serviços de apoio para as pessoas idosas vítimas de violência como abrigos, encaminhamento para outros profissionais, apoios sociais, financeiros e emocionais podem ser de grande relevância.

O presente estudo apresenta limitações próprias dos estudos que utilizam dados secundários, como casos de possíveis subnotificações e incompletude de informações, o que pode comprometer a análise. Outro fator que pode implicar na fidedignidade dos dados sobre a violência que necessitam de atendimento de saúde, é que abrangência do sistema está limitada às notificações no âmbito do SUS, excluindo, portanto, as que são atendidas diretamente por seguro-saúde ou particulares.

\section{Conclusão}

Os resultados apontam um aumento a cada ano do registro de violência contra os idosos na região Nordeste no período de 2012 a 2018, destacando-se o estado de Pernambuco como o maior número de casos. O presente estudo permitiu ainda identificar algumas características dos idosos que sofreram violência mostrando que as vítimas em sua maioria são do sexo feminino, pardas e com baixa escolaridade. No que tanges a essa situação, vale mencionar que estes dados são semelhantes com os da literatura. Tais achados evidenciam que o perfil da morbidade pela violência contra os idosos no Nordeste é influenciado principalmente pelas desigualdades sociais.

Considerando que o local onde mais ocorreu a violência foi na própria residência e a natureza mais frequente foi representado pela agressão física, denota ser o domicílio o local de maior risco, onde deveria ser um local de acolhimento e refúgio para o idoso.

A violência contra a pessoa idosa é uma ocorrência de baixa notificação no Brasil, com isso, é necessário que sejam feitos mais estudos que trabalhem com esta temática, para aumentar a visibilidade do problema e elaborar estratégias efetivas de prevenção e assistência. 
Acredita-se que os resultados deste estudo possam ser usados para elaborar estratégias de prevenção com base em medidas educativas para a população que contribua para a construção de uma rede apoiadora à pessoa idosa, buscando motivações para quebrar o silêncio e estimular as notificações, a fim de reduzir os casos de violência contra esse público.

\section{Contribuições individuais}

Lima IVS e Palmeira CS participaram da concepção do projeto, busca, organização e análise dos dados, interpretação dos resultados, redação do artigo científico e aprovação final da versão a ser submetida para publicação. Macedo TTSM participou da interpretação dos resultados, redação do artigo científico e aprovação final da versão a ser submetida para publicação.

\section{Conflito de interesses}

Nenhum conflito financeiro, legal ou político envolvendo terceiros (governo, empresas e fundações privadas, etc.) foi declarado para nenhum aspecto do trabalho submetido (incluindo, mas não se limitando a subvenções e financiamentos, participação em conselho consultivo, desenho de estudo, preparação de manuscrito, análise estatística, etc.).

\section{Referências}

1. Canêdo AC, Lopes CS, Lourenço RA. Prevalence of and factors associated with successful aging in Brazilian older adults: frailty in Brazilian older people Study (FIBRA RJ). Geriatr Gerontol Int. 2018;18(8):1280-5. https://doi.org/10.1111/ggi.13334

2. Barbosa KTF, Oliveira FMRL, Fernandes MGM. Vulnerabilidade da pessoa idosa: Análise conceitual. Rev Bras Enferm.

2019;72(2):352-360. https://doi.org/10.1590/0034-7167-2018-0728

3. Pillemer K, Burnes D, Riffin C, Lachs MS. Elder Abuse: Global Situation, Risk Factors, and Prevention Strategies. Gerontologist. 2016;56(Suppl 2):194-205. https://doi.org/10.1093/geront/gnw004

4. World Health Organization. Elder abuse [Internet]. Who; 2020. Disponível em: https://www.who.int/news-room/fact-sheets/ detail/elder-abuse

5. Yon Y, Mikton CR, Gassoumis ZD, Wilber KH. Elder abuse prevalence in community settings: a systematic review and metaanalysis. The Lancet. 2017; 5(2):E147-56. https://doi.org/10.1016/ s2214-109X(17)30006-2
6. Manso MEG. Dossiê - Violência contra a pessoa idosa. Diversas faces da mesma moeda. Rev. Longeviver [Internet]. 2019;1(3):7580. Disponível em: https://revistalongeviver.com.br/index.php/ revistaportal/article/view/796

7. Castro VC, Rissardo LK, Carreira L. Violência contra os idosos brasileiros: uma análise das internações hospitalares. Rev. Bras. Enferm. 2018;71(Supl 2):777-85. https://doi.org/10.1590/00347167-2017-0139

8. Garbin CAS, Joaquim RC, Rovida TAS, Garbin AJl. Idosos vítimas de maus-tratos: cinco anos de análise documental. Revista bras geriatr gerontol. 2016;19(1):87-94. https://doi.org/10.1590/18099823.2016.15037

9. World Health Organization. The Toronto declaration on the global prevention of elder abuse [Internet]. Geneva: WHO; 2002. [citado em 2020 Jan 16]. Disponível em: https://www.who.int/ ageing/projects/elder abuse/alc toronto declaration en.pdf

10. Lachs MS, Pillemer KA. Elder abuse. N Engl J Med. 2015;373(20):1947-56. https://doi.org/10.1056/nejmra1404688

11. Ministério da Saúde, Secretaria de Atenção à Saúde. Estatuto do Idoso [Internet]. 3a ed. Brasília: Ministério da Saúde; 2013. Disponível em: https://bvsms.saude.gov.br/bvs/publicacoes/ estatuto_idoso_3edicao.pdf

12. Portaria $n^{\circ} 104$, de 25 de janeiro de 2011 (Brasil). Define as terminologias adotadas em legislação nacional, conforme o disposto no Regulamento Sanitário Internacional 2005 (RSI 2005), a relação de doenças, agravos e eventos em saúde pública de notificação compulsória em todo o território nacional e estabelece fluxo, critérios, responsabilidades e atribuições aos profissionais e serviços de saúde. [Internet]. Diário Oficial da União. 26 Jan 2011. Disponível em: https://bvsms.saude.gov.br/ bvs/saudelegis/gm/2011/prt010425 01 2011.html

13. Lei n. 10.741 , de $1^{\circ}$ de outubro de 2003 (Brasil). Dispõe sobre o Estatuto do Idoso e dá outras providências. [Internet]. Diário Oficial da União. 2003 out. 1. Disponível em: http://www.planalto. gov.br/ccivil_03/leis/2003/l10.741.htm

14. Camacho ACLF, Alves RR. Maus tratos contra os idosos na perspectiva da enfermagem: revisão integrativa. Rev enferm UFPE on line. 2015;9(2):927-35. Disponível em: https://periodicos.ufpe. br/revistas/revistaenfermagem/article/view/10418

15. Minayo MCS, Souza ER, Paula DRD. Revisão sistemática da produção acadêmica brasileira sobre causas externas e violências contra a pessoa idosa. Ciência \& Saúde Coletiva. 2010;15(6):271928. https://doi.org/10.1590/S1413-81232010000600010

16. Santos MAB, Moreira RS, Faccio PF, Gomes GC, Silva VL. Fatores associados à violência contra o idoso: Uma revisão sistemática da literatura. Ciênc saúde coletiva. 2020;25(6):215375. https://doi.org/10.1590/1413-81232020256.25112018 
17. Paraíba PMF, Silva MCM. Perfil da violência contra a pessoa idosa na cidade do Recife-PE. Rev. bras. geriatr. gerontol. 2015:18(2):295-306. https://doi.org/10.1590/1809$\underline{9823.2015 .14047}$

18. Ho CS, Wong SY, Chiu MM, Ho RC. Global Prevalence of Elder Abuse: A Meta-analysis and Meta-regression. East Asian Arch Psychiatry. 2017;27(2):43-55. Citado em: PMID: 28652497

19. Rodrigues RAP, Monteiro EA, Santos AMR, Pontes MLF, Fhon JRS, Bolina AF, et al. Violência contra idosos em três municípios brasileiros. Rev. Bras. Enferm. 2017;70(4):783-91. https://doi. org/10.1590/0034-7167-2017-0114

20. Secretaria de Direitos Humanos da Presidência da República. Brasil: manual de enfrentamento à violência contra a pessoa idosa. É possível prevenir. É necessário superar [Internet]. Brasília, DF: Secretaria de Direitos Humanos da Presidência da República; 2014. Disponível em: http://www.dive.sc.gov.br/conteudos/ agravos/publicacoes/manual-de-enfrentamento-a-violenciacontra-a-pessoa-idosa.pdf

21. Bolsoni CC, Coelho EBS, Giehl MWC, Orsi ED. Prevalência de violência contra idosos e fatores associados, estudo de base populacional em Florianópolis, SC. Rev. bras. geriatr. gerontol. 2016;19(4):671-82. https://doi.org/10.1590/180998232016019.150184
22. Maia PHS, Ferreira EF, Melo EM, Vargas AMD. A ocorrência da violência em idosos e seus fatores associados. Rev. bras. geriatr. gerontol. 2019;72(Supl 2):64-70. https://doi.org/10.1590/00347167-2018-0014

23. Santana IO, Vasconcelos DC, Coutinho MPL. Prevalência da violência contra o idoso no Brasil: revisão analítica. Arq. bras. Psicol [Internet]. 2016;6(1):126-39. Disponível em: http://pepsic.bvsalud.org/scielo.php?script=sci_ arttext\&pid=S1809-52672016000100011

24. Simone L, Wettstein A, Senn O, Rosemann T, Hasler S. Types of abuse and risk factors associated with elder abuse. Swiss Med Wkly. 2016;146:w14273. https://doi.org/10.4414/smw.2016.14273

25. Paiva MM, Tavares DMS. Violência física e psicológica contra idosos: Prevalência e fatores associados. Rev Bras Enferm. 2015;68(6):1035-41. https://doi.org/10.1590/0034$\underline{7167.2015680606 \mathrm{i}}$ 